\title{
Author Correction: Molecular architecture of the multifunctional collagen lysyl hydroxylase and glycosyltransferase LH3
}

\author{
Luigi Scietti', Antonella Chiapparino (10 1, Francesca De Giorgi (i) 1, Marco Fumagalli², Lela Khoriauli id ${ }^{3}$, \\ Solomon Nergadze (i) ${ }^{3}$, Shibom Basu ${ }^{4}$, Vincent Olieric (1) 4, Lucia Cucca5 , Blerida Banushi6,8, \\ Antonella Profumo ${ }^{5}$, Elena Giulotto ${ }^{3}$, Paul Gissen (i) ${ }^{6,7}$ \& Federico Forneris (i) ${ }^{1}$
}

Correction to: Nature Communications; https://doi.org/10.1038/s41467-018-05631-5; published online 08 August 2018

The previously published version of this Article contained an error in Fig. 3. In Fig. 3a, the residues His667 and Asp669 were incorrectly labelled as His627 and Asp629. The error has been corrected in both the PDF and HTML versions of the Article.

Published online: 20 September 2018

\begin{abstract}
(c) (i) Open Access This article is licensed under a Creative Commons Attribution 4.0 International License, which permits use, sharing, adaptation, distribution and (c) reproduction in any medium or format, as long as you give appropriate credit to the original author(s) and the source, provide a link to the Creative Commons license, and indicate if changes were made. The images or other third party material in this article are included in the article's Creative Commons license, unless indicated otherwise in a credit line to the material. If material is not included in the article's Creative Commons license and your intended use is not permitted by statutory regulation or exceeds the permitted use, you will need to obtain permission directly from the copyright holder. To view a copy of this license, visit http://creativecommons.org/licenses/by/4.0/.
\end{abstract}

() The Author(s) 2018

\footnotetext{
${ }^{1}$ The Armenise-Harvard Laboratory of Structural Biology, Department of Biology and Biotechnology, University of Pavia, Via Ferrata 9/A, 27100 Pavia, Italy. ${ }^{2}$ Laboratory of Biochemistry, Department of Biology and Biotechnology, University of Pavia, Via Taramelli 3/B, 27100 Pavia, Italy. ${ }^{3}$ Laboratory of Molecular Biology, Department of Biology and Biotechnology, University of Pavia, Via Ferrata 9/A, 27100 Pavia, Italy. ${ }^{4}$ Swiss Light Source, Paul Scherrer Institut Villigen 5232, Switzerland. ${ }^{5}$ Laboratory of Analytical Chemistry, Department of Chemistry, University of Pavia, Via Taramelli 12,27100 Pavia, Italy. ${ }^{6}$ MRC Laboratory for Molecular Cell Biology, University College London, WC1E 6BT London, UK. 7 UCL Great Ormond Street Institute of Child Health, 30 Guilford Street, WC1N 1EH London, UK. ${ }^{8}$ Present address: Translational Research Institute, The University of Queensland Diamantina Institute, Princess Alexandra Hospital, 37 Kent Street, Brisbane, Australia. The original article can be found online at https://doi.org/10.1038/s41467-018-05631-5. Correspondence and requests for materials should be addressed to F.F. (email: federico.forneris@unipv.it)
} 